\title{
Indirect detection of organic acids in non-aqueous capillary electrophoresis
}

\author{
Min-Jane Chen ${ }^{\mathrm{a}}$, Hsuan-Shen Chen ${ }^{\mathrm{b}}$, Cheng-Yi Lin ${ }^{\mathrm{c}}$, Huan-Tsung Chang ${ }^{\mathrm{b}, *}$ \\ ${ }^{a}$ Department of Food Science, National Chiayi Institute of Technology, Chiayi, Taiwan \\ ${ }^{\mathrm{b}}$ Department of Chemistry, National Taiwan University, P.O. Box 23-34, Taipei, Taiwan \\ ${ }^{\mathrm{c}}$ Department of Agriculture Chemistry, National Taiwan University, Taipei, Taiwan
}

\begin{abstract}
Non-aqueous capillary electrophoresis (NACE) with indirect detection has been applied to the determination of fatty acids (FAs) and ascorbic acid (AA), respectively. $\mathrm{C}_{2}-\mathrm{C}_{18}$ FAs have been separated in less than 12 min using 8-hydroxy-7iodoquinoline sulfonic acid as chromophores in NACE with indirect absorbance. The dissociation constant $\left(\mathrm{p} K_{\mathrm{a}}\right)$ values of $\mathrm{C}_{8}-\mathrm{C}_{18}$ FAs obtained from the slope of the linear plot $-\log \left[\left(\mu_{0} / \mu\right)-1\right]$ vs. $\mathrm{pH}$, using $20 \%$ isopropanol and $40 \%$ acetonitrile as the organic modifier in NACE, are all above about two units than those obtained in aqueous solution. NACE with indirect laser-induced fluorescence, using merocyanine 540 (MC540) as fluorophores, has been performed to the analysis of AA and its stereoisomer, isoascorbic acid (IAA), and the limits of detection of AA and IAA are $0.30 \mu M$ and $0.17 \mu M$, respectively. This method has been applied to the determination of AA in a lemon juice spiked with IAA as the internal standard in less than $3 \mathrm{~min}$ and its concentration is $76.7 \pm 0.4 \mathrm{mM}$. (C) 1999 Elsevier Science B.V. All rights reserved.
\end{abstract}

Keywords: Non-aqueous capillary electrophoresis; Detection, electrophoresis; Indirect detection; Organic acids; Fatty acids; Ascorbic acid; Isoascorbic acid

\section{Introduction}

The analysis of organic acids, such as fatty acids (FAs) and ascorbic acid (AA), is of importance in food technology and physiology since these acids play important roles in the metabolism of living beings, and widely exist in a number of foods [1-3]. Generally, these acids are determined by using gas chromatography (GC) and high-performance liquid chromatography (HPLC) [4-6]. Although these

\footnotetext{
*Corresponding author. Tel.: +886-2-2362-1963; fax: +886-22362-1963.

E-mail address: changht@mail.ch.ntu.edu.tw (H.-T. Chang)
}

methods are commonly used, alternative approaches giving faster analysis, preferably without any tedious derivatization process, are still needed.

Capillary electrophoresis (CE) provides high-resolution and high-speed separations of a variety of solutes and has become popular in the analysis of acids for almost two decades [7,8]. However, problems such as the poor solubility of FAs in aqueous solutions and the lack of sensitive detection modes for aliphatic acids are common in CE. To overcome these shortages, non-aqueous capillary electrophoresis (NACE) with indirect detection seems to be a suitable approach.

Recently, NACE has been proved useful for the separation of a number of solutes including inorganic 
and organic ions [9]. CE separations of FAs have been demonstrated using 60\% acetonitrile [10], 30\% methanol and Brij 35 [11], or $60 \%$ methanol solutions containing cyclodextrins (CDs) [12]. Micellar electrokinetic capillary chromatography (MECC) using sodium dodecyl benzenesulfate (SDBS), 50\% acetonitrile, and Brij 35 was also applied to the analysis of FAs [13]. MECC with sodium deoxycholate has also been applied to the determination of ascorbic acid in vegetables [14]. All these techniques show that organic solvent, detergent, $\mathrm{CD}$, and $\mathrm{pH}$ affect the electroosmotic flow (EOF) and resolution in the separation of acids. However, the effects of chromophores and fluorophores on the EOF and separation results have not been carefully elucidated in NACE.

A number of different detection modes have been developed for the analysis of organic acids, including direct absorbance for AA at the UV range [15-17], indirect absorbance (IA) in non-aqueous solutions for FAs [12,18], and laser-induced fluorescence with tedious derivatization processes for FAs $[19,20]$. However, these methods either suffer from low sensitivity or are time consuming. Thus a method providing high sensitivity and universal characteristics is still needed. From this view, indirect laserinduced fluorence (ILIF) seems to be very optimistic for the analysis of small amounts of organic acids [21]. Unfortunately, to date, only few examples have been reported for the analysis of acids via NACE with ILIF (NACE-ILIF) [22].

Recently, many relatively hydrophobic fluorophores have been synthesized and applied to the analysis of a number of important solutes using low-cost lasers, such as a He-Ne laser [23]. Therefore, it is worthy taking advantage of new fluorophores and the laser technology to develop novel methods for the determination of trace amounts of acids using NACE-ILIF. In this report, we demonstrated two different methods for the analysis of organic acids: FAs in NACE-IA using 8-hydroxy-7iodoquinoline (HIQSA) as the chromophores and AA in NACE-ILIF using MC540 as the fluorophores. The effects of organic solvent and $\mathrm{pH}$ on the EOF and on the separation of $\mathrm{C}_{2}-\mathrm{C}_{18}$ FAs were carefully elucidated. NACE-ILIF was also performed for detecting AA in a real sample.

\section{Experimental}

\subsection{Capillary electrophoretic system}

A commercial electrophoretic instrument from Bio-Rad (BioFocus CE 2000, Hercules, CA, USA) was used and the wavelength was set at $250 \mathrm{~nm}$ in NACE-IA. The basic design of the NACE-ILIF system has been previously described [24]. Briefly, a high-voltage power supply (Gamma High Voltage Research, Ormond Beach, FL, USA) was used to drive the electrophoresis. The entire detection system was enclosed in a black box with a high-voltage interlock. The high-voltage end of the separation system was put in a home-made plexiglass box for safety. A $1.5-\mathrm{mW} \mathrm{He}-\mathrm{Ne}$ laser with $543.6 \mathrm{~nm}$ output from Melles Griot (Irvine, CA, USA) was used for excitation. The light was collected with a $10 \times$ objective (N.A. $=0.25$ ). One RG 610 cutoff filter was used to block scattered lights before the emitted light reached the phototube (Hamamatsu R928). The fluorescence signal was directly transferred through a $10-\mathrm{k} \Omega$ resistor to a 24-bit A/D interface at $10 \mathrm{~Hz}$ (Borwin, JMBS Developments, Le Fontanil, France) and stored in a personal computer.

The fused-silica capillaries (Polymicro Technologies, Phoenix, AZ, USA) used in NACE-IA and NACE-ILIF were $35 \mathrm{~cm}$ (30 cm effective length $) \times$ $75 \mu \mathrm{m}$ I.D., and $40 \mathrm{~cm}(30 \mathrm{~cm}$ effective length $) \times 75$ $\mu \mathrm{m}$ I.D., respectively.

\subsection{Chemicals}

All chemicals were of reagent grade and were obtained from Sigma (St. Louis, MO, USA), except for HIQSA, which was from Matheson Coleman \& Bell (Cincinnati, OH, USA). Buffer solutions used in this work were addressed in Section 3. Briefly, diluted $\mathrm{H}_{3} \mathrm{PO}_{4}$ and/or $\mathrm{NaOH}$ solutions were used to adjust buffer $\mathrm{pH}$. The lemon juice used for the analysis of AA was made by Wei-Chuan (Tainan, Taiwan) and bought from a local store.

\subsection{Electrophoretic procedures}

New capillaries were rinsed with $0.1 M \mathrm{NaOH}$ overnight. Prior to analysis, capillaries were rinsed 
Table 1

Physical and chemical properties of solvents used in this work

\begin{tabular}{lllll}
\hline Solvent & $\begin{array}{l}\text { Viscosity } \\
(\mathrm{cP})\end{array}$ & $\begin{array}{l}\text { Dipole } \\
\text { moment }\end{array}$ & $\begin{array}{l}\text { Dielectric } \\
\text { constant }\end{array}$ & $\mathrm{p} K_{\text {auto }}$ \\
\hline Water & 0.89 & 1.87 & 78.5 & 14.00 \\
Methanol & 0.54 & 2.87 & 32.7 & 17.20 \\
Acetonitrile & 0.33 & 3.44 & 37.5 & $>33.3$ \\
Isopropanol & 0.78 & 1.66 & 18.3 & - \\
\hline
\end{tabular}

with $0.1 M \mathrm{NaOH}$ for $3 \mathrm{~min}$, then flushed with running buffers for $20 \mathrm{~s}$. Prior to the analysis using different buffer solutions, capillaries were always rinsed with $0.1 M \mathrm{NaOH}$ overnight. Samples of 50 $\mu M$ FAs were injected into capillaries by hydrodynamic injection at level three (pressure $\times$ time) in NACE-IA. AA and isoascorbic acid (IAA) were injected at $30 \mathrm{~cm}$ height for $5 \mathrm{~s}$ in NACE-ILIF. The separation was performed at $18 \mathrm{kV}$ in NACE-IA and $15 \mathrm{kV}$ in NACE-ILIF, respectively.

\subsection{Calculations}

Resolution $\left(\mathrm{R}_{\mathrm{s}}\right)$ was calculated using Eq. (1)

$R_{\mathrm{s}}=2\left(t_{2}-t_{1}\right) /\left(t_{\mathrm{w} 1}+t_{\mathrm{w} 2}\right)$

where $t_{1}$ and $t_{2}$ are the migration times and $t_{\mathrm{w} 1}$ and $t_{\mathrm{w} 2}$ are the peak widths at baseline for components 1 and 2, respectively. The limit of detection (LOD) was calculated using a signal-to-noise ratio $(S / N)$ of 3. The EOF and the electrophoretic mobilities (EPMs) of analytes were calculated from the migration times of the peaks corresponding to solvent and the analytes, respectively.

\section{Results and discussion}

\subsection{Effects of organic solvents}

The $\zeta$ potential of the capillary wall, and the viscosity and dielectric constant of the buffer solution significantly affect the EOF and EPMs of analytes. Therefore, the choice of buffer solutions, with respects to $\mathrm{pH}$, viscosity and polarity, is important. Table 1 shows some physical and chemical properties of solvents used in this work. Generally, a solvent with low viscosity, such as acetonitrile $(\mathrm{ACN})$, is preferred for high-speed separations. ACN is also a very weak acid as well as a very weak base and therefore it is a good differentiating solvent for acids. However its aprotic characteristics makes it a less suitable solvent for the electrolytes. To overcome this shortage, it is generally suggested to add a protic solvent, such as isopropanol $(i-\mathrm{PrOH})$ and acetic acid, to improve the solubility of electrolytes and FAs considerably.

Table 2 shows that the EOF increased about 2.5 times as the concentration (\%) ratios of $i-\mathrm{PrOH}$ to $\mathrm{ACN}$ were changed from 2 to 0.2 in NACE-IA. On the other hand, the EPM values of FAs shown in Fig. 1 increased less than 2 times. It clearly indicates that the high EOF and high EPM values of FAs can be obtained with the decrease in viscosity of the buffer (higher \% ACN). In addition, the effects of the organic modifier on the dissociation of the silanol groups in the capillary wall and the carboxylic group in FAs might also be considered for affecting the separation results [25]. Furthermore, the adsorption of the electrolytes, such as HIQSA, onto the capillary wall under various conditions may also affect the EOF differently. Table 2 also shows the reduction of

Table 2

Effects of organic solvents on the EOF

\begin{tabular}{|c|c|c|c|c|c|c|c|}
\hline \multirow[b]{3}{*}{ Concentration (ratio) } & \multicolumn{7}{|c|}{ Organic modifier in the buffer } \\
\hline & \multicolumn{4}{|c|}{$i-\mathrm{PrOH}-\mathrm{ACN}^{\mathrm{a}, \mathrm{b}}$} & \multicolumn{3}{|c|}{ Methanol $(\mathrm{v} / \mathrm{v} \%)^{\mathrm{c}}$} \\
\hline & 2 & 1 & 0.5 & 0.2 & 0 & 40 & 60 \\
\hline $\operatorname{EOF}\left(\times 10^{-4} \mathrm{~cm}^{2} \mathrm{~V}^{-1} \mathrm{~s}^{-1}\right)$ & 2.4 & 3.5 & 4.4 & 5.9 & 3.9 & 3.4 & 2.6 \\
\hline
\end{tabular}

\footnotetext{
${ }^{a}$ Measured in the NACE-IA system using $0.2 \mathrm{~m} M$ HIQSA as the chromophores at $\mathrm{pH} 7.2$.

${ }^{\mathrm{b}}$ The total concentration of $i$-PrOH and ACN remained constant $(60 \%)$.

${ }^{\mathrm{c}}$ Measured in the NACE-ILIF system using $10 \mu M$ MC540 as the fluorophores at pH 4.0.
} 


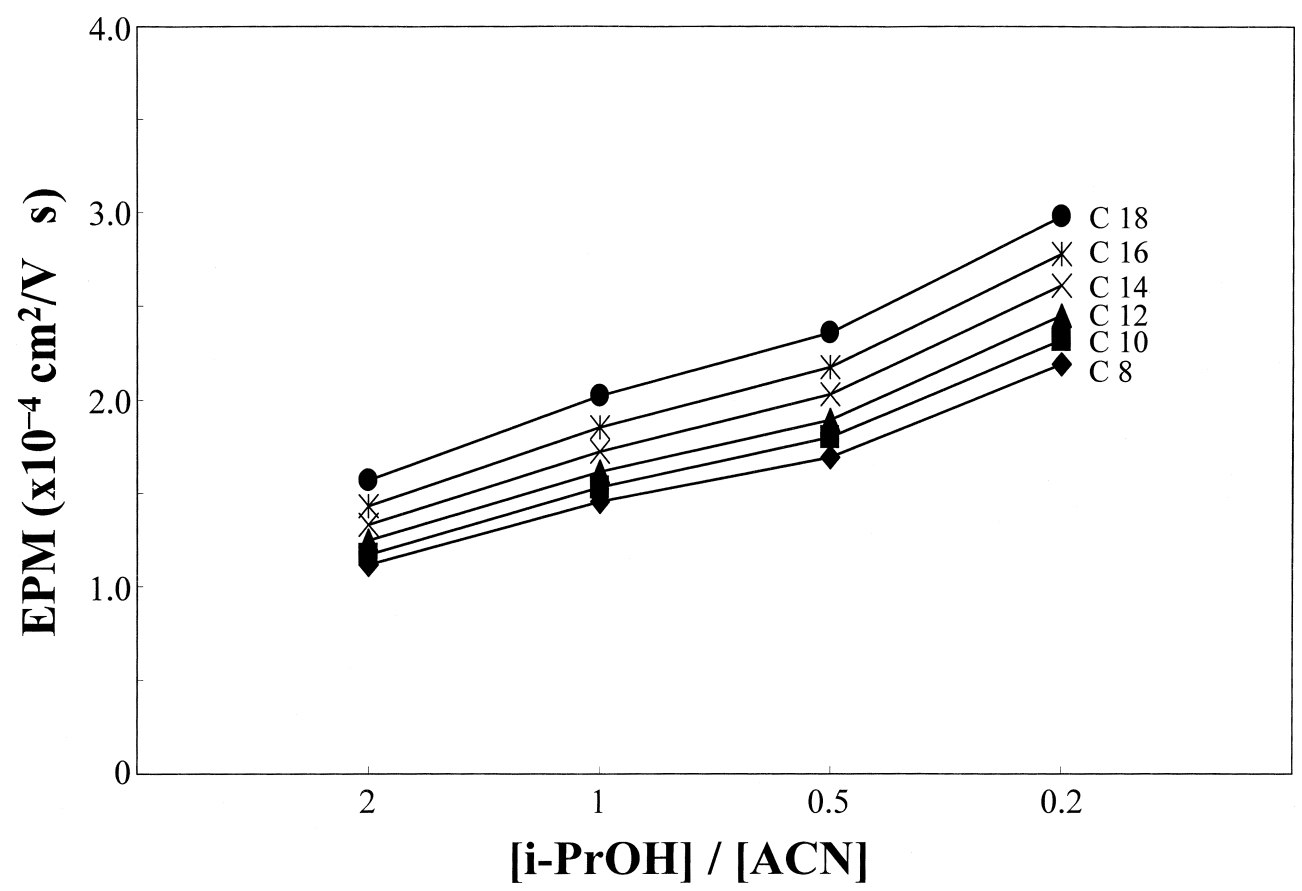

Fig. 1. The EPM values of $\mathrm{C}_{8}-\mathrm{C}_{18}$ FAs obtained in NACE-IA, using $0.2 \mathrm{~m} M$ HIQSA, $1 \mathrm{~m} M$ phosphate, and various $\% i$-PrOH and ACN (total concentration $=60 \%$ ); buffer solutions, $\mathrm{pH} 7.2$; capillary, $35 \mathrm{~cm}(30 \mathrm{~cm}$ effective length) $\times 75 \mu \mathrm{m}$ I.D. $\times 365 \mu \mathrm{m}$ O.D; detection wavelength, $250 \mathrm{~nm}$.

the EOF with increases in the concentration of methanol at $\mathrm{pH} 4.0$ in NACE-ILIF. In addition to the effects from the change in buffer viscosity, a dramatic decrease in the negatively charged density of the capillary wall at such low $\mathrm{pH}$ and high \% methanol might be possible for the decrease in the EOF. Transient changes due to buffer electrolysis in the system might occur since the separations were performed under nonequilibrium conditions [26,27]. Furthermore, the adsorption of merocyanine 540 (MC540; more hydrophobic than HIQSA) onto the capillary wall may account for the dramatic changes in the EOF at such low $\mathrm{pH}$, which was supported by our observation that the EOF dramatically decreases when MC540 concentration is higher than $0.5 \mu M$ in aqueous solutions at $\mathrm{pH}$ 4.0.

Fig. 2 shows that only resolution between $\mathrm{C}_{8}$ and $\mathrm{C}_{10}$ FAs decreases with increases in the fraction of $\mathrm{ACN}$ in the running buffer and others show irregular changes. The smaller differences of the migration velocities among FAs using lower viscous solutions (high EOF) result in the loss in resolution. The loss may also be due to the poor solvation capability of the organic buffers, which in turn causes smaller differences in $\mathrm{p} K_{\mathrm{a}}$ values among FAs. The differentiating capability of $\mathrm{ACN}\left(\mathrm{p} K_{\text {auto }}>33.3\right.$ ) for acids is even worse for small FAs since they are relatively hydrophilic. In terms of reproducibility and separation speed we chose $20 \%$ isopropanol and $40 \%$ $\mathrm{ACN}$ as the organic modifier for latter studies. Under these condition, RSD (migration time) of octanoic acid is less than $0.3 \%$.

\subsection{Effects of $p H$}

Fig. 3 shows that the EOF significantly increased between pH 6.9 and 7.5 using $20 \% i$-PrOH and $40 \%$ ACN as the organic modifier in NACE-IA, and the EPM values of FAs also increased with increases in buffer $\mathrm{pH}$ between 6.9 and 9.1. On the other hand, Fig. 4 shows that the EOF dramatically increased above $\mathrm{pH} 7$ in NACE-ILIF, which is about two $\mathrm{pH}$ units higher than that in aqueous solutions [28,29]. The result suggested that the dissociation constant of 


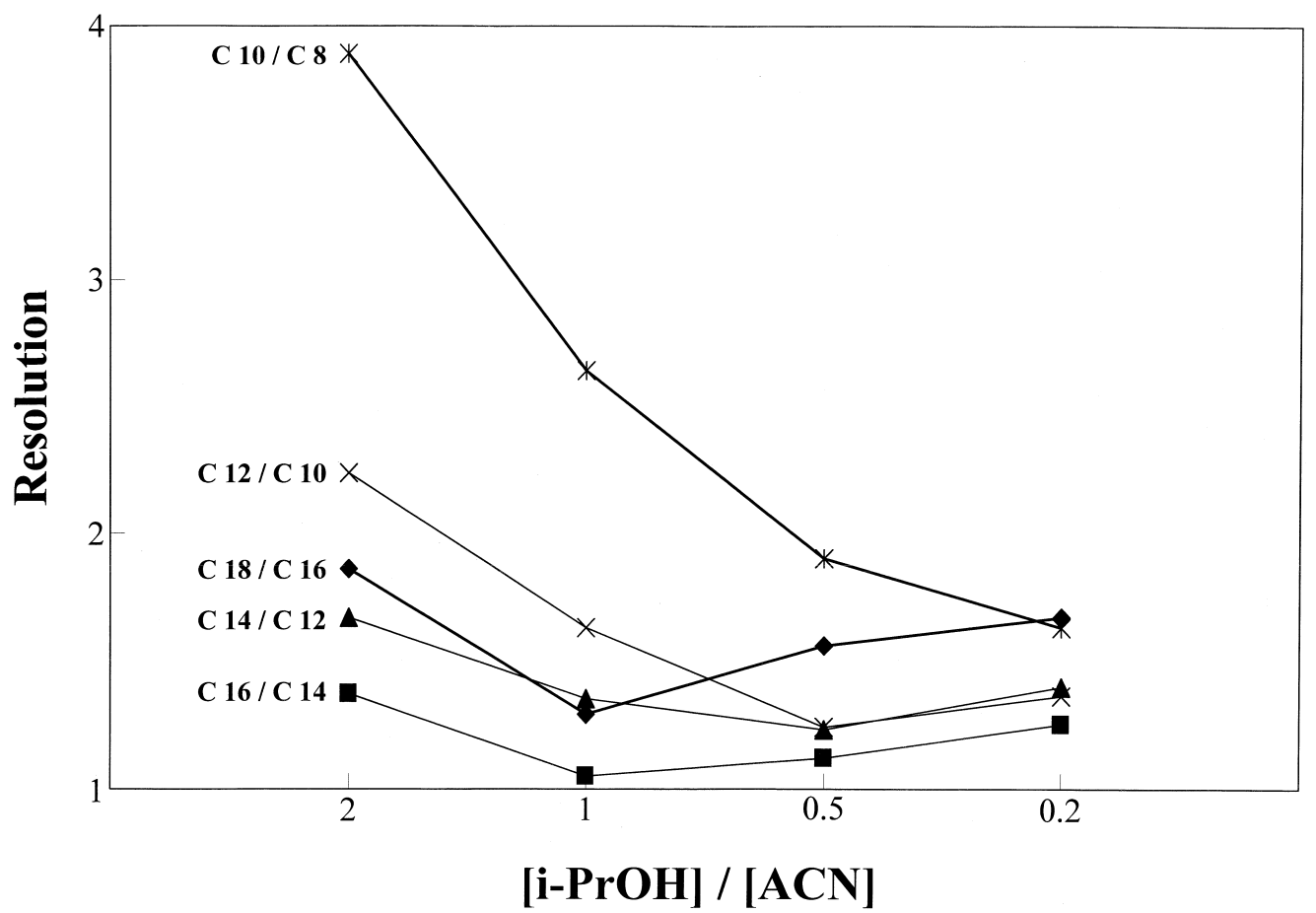

Fig. 2. The effects of organic modifiers on resolution in the separation of $\mathrm{C}_{8}-\mathrm{C}_{18}$ FAs in NACE-IA. Conditions as in Fig. 1 .

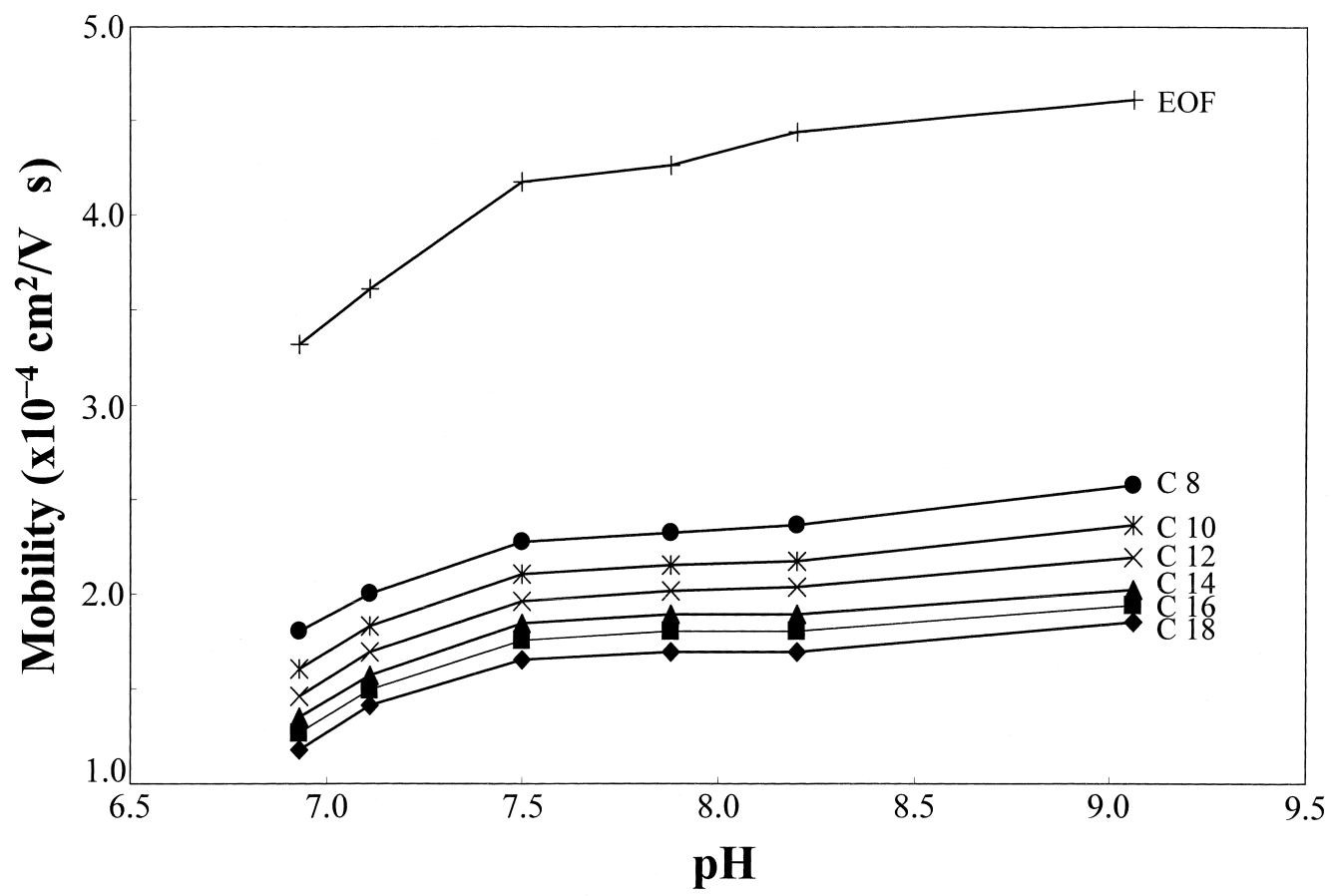

Fig. 3. $\mathrm{pH}$ effects on EOF and the EPMs of $\mathrm{C}_{8}-\mathrm{C}_{18}$ FAs in NACE-IA, using $0.2 \mathrm{~m} M$ HIQSA, $1 \mathrm{~m} M$ phosphate, $20 \% i$-PrOH and $40 \%$ ACN buffer solutions. Other conditions as in Fig. 1. 


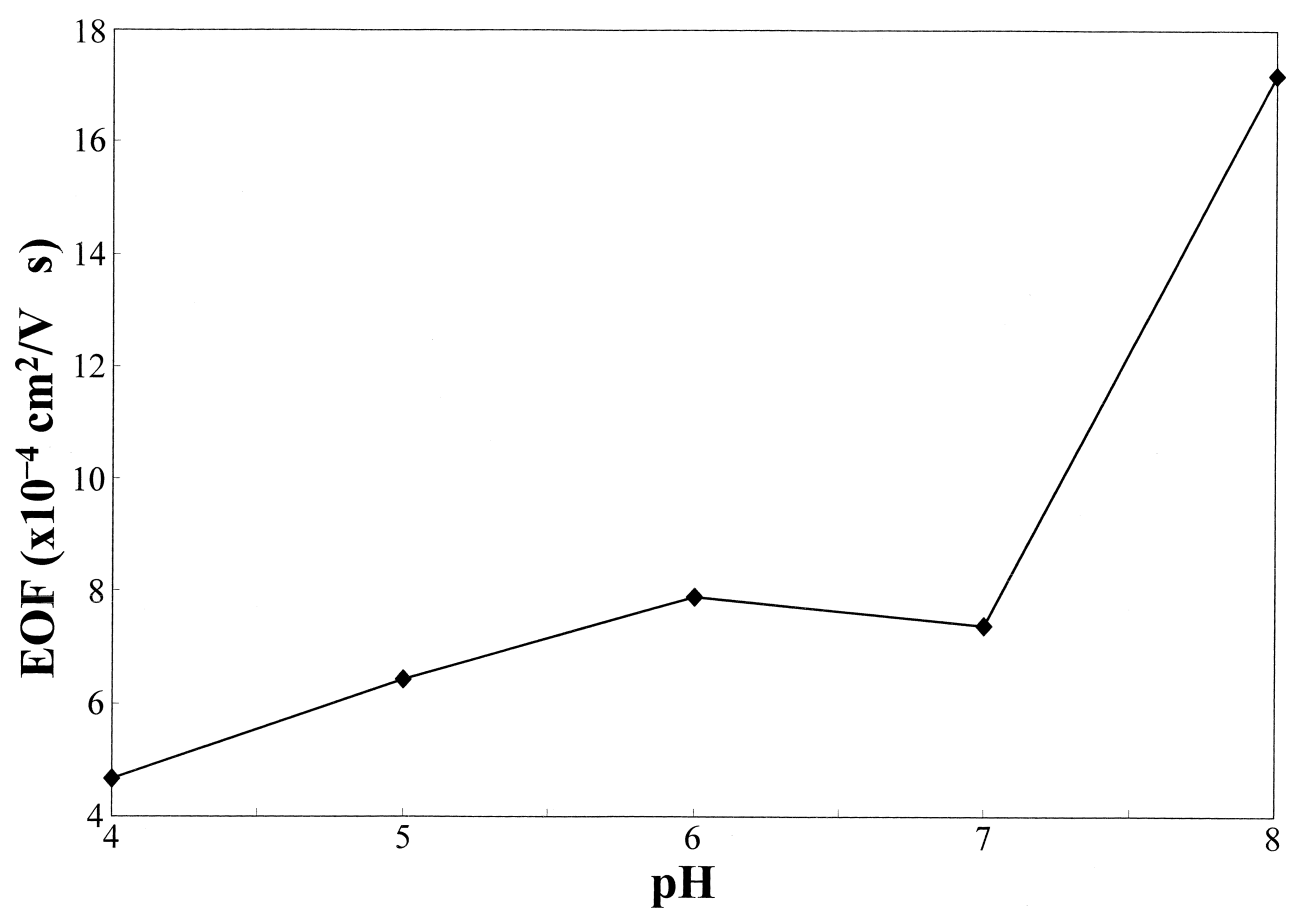

Fig. 4. pH effects on EOF in NACE-ILIF, using $30 \mu M$ MC540 and $40 \%$ methanol buffer solutions. Capillary, $40 \mathrm{~cm}(30 \mathrm{~cm}$ effective length).

the silanol group in organic solutions is different (about $2 \mathrm{pH}$ units higher) from that in aqueous solutions. A higher EOF obtained in NACE-ILIF than that in NACE-IA was due to much lower ionic strengths used in the former. A stronger interaction between the capillary wall and MC540 under lower $\mathrm{pH}$ conditions may also account for the observation. Theoretically, MC540 affected the EOF slightly less at higher $\mathrm{pH}$ since it is more hydrophilic.

\subsection{Dissociation constant}

In NACE, the degree of dissociation of an acid $\left(\alpha_{\mathrm{A}-}\right)$ can be calculated from Eq. (2):

$$
\alpha_{\mathrm{A}-}=\left[\mathrm{A}^{-}\right] /\left([\mathrm{HA}]+\left[\mathrm{A}^{-}\right]\right)=\mu / \mu_{0}
$$

where $\left[\mathrm{A}^{-}\right]$and $[\mathrm{HA}]$ are the concentrations of the anion and acid, respectively, and $\mu$ and $\mu_{0}$ are the EPM values of anions at a certain $\mathrm{pH}$ and $\mathrm{pH} 9.1$ (wherein the acid completely dissociated), respectively. In order to calculate $\mathrm{p} K_{\mathrm{a}}$ values of FAs from the results shown in Fig. 3, we rewrote Eq. (2) to Eq. (3):

$-\log \left[\left(\mu_{0} / \mu\right)-1\right]=\mathrm{pH}-\mathrm{p} K_{a}$

Thus, we could obtain the $\mathrm{p} K_{\mathrm{a}}$ values of FAs from the slope of the linear plot of $-\log \left[\left(\mu_{0} / \mu\right)-1\right]$ vs. $\mathrm{pH}$. Table 3 shows that the $\mathrm{p} K_{\mathrm{a}}$ values of FAs obtained in NACE-IA are between 6 and 7, which are about 2 units higher than those obtained in aqueous solution.

Table 3

$\mathrm{p} K_{\mathrm{a}}$ values of FAs obtained in NACE-IA

\begin{tabular}{ll}
\hline Acids & $\mathrm{p} K_{\mathrm{a}}(n=5)$ \\
\hline $\mathrm{C}_{18}$ & $6.64 \pm 0.05$ \\
$\mathrm{C}_{16}$ & $6.68 \pm 0.04$ \\
$\mathrm{C}_{14}$ & $6.67 \pm 0.04$ \\
$\mathrm{C}_{12}$ & $6.63 \pm 0.06$ \\
$\mathrm{C}_{10}$ & $6.59 \pm 0.05$ \\
$\mathrm{C}_{8}$ & $6.49 \pm 0.06$ \\
\hline
\end{tabular}




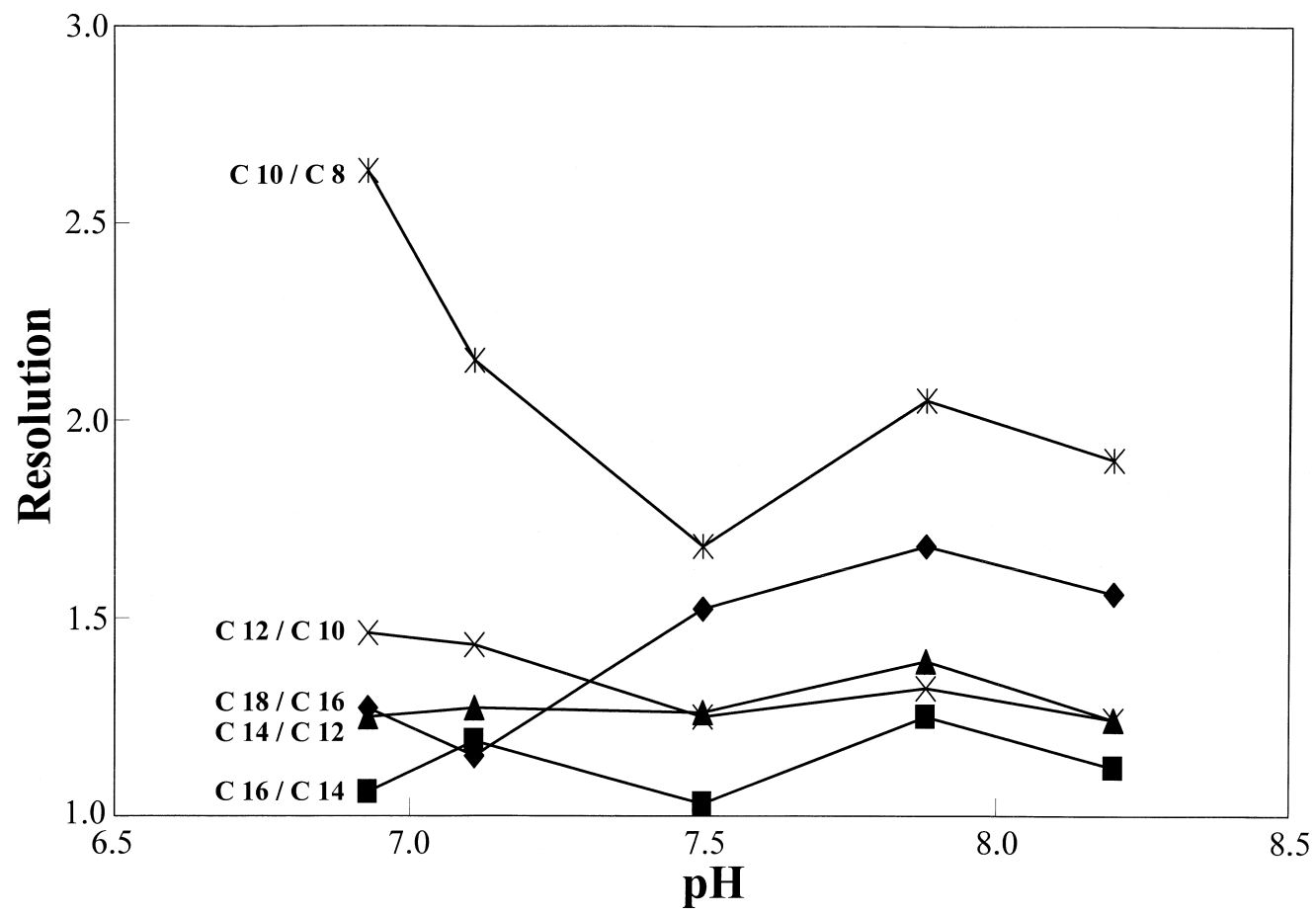

Fig. 5. $\mathrm{pH}$ effects on resolution in the separation of FAs in NACE-IA. Other conditions as in Fig. 3.

\subsection{Resolution}

Fig. 5 shows that resolution in the separation of FAs changed as buffers were varied from $\mathrm{pH} 6.5$ to 8.5, and all FAs were only resolved at $\mathrm{pH} 7.2$ and $\mathrm{pH}$ 7.8. The trend also shows that the separation performed under lower $\mathrm{pH}$ conditions are better for the separation of small organic acids (lower $\mathrm{p} K_{\mathrm{a}}$ values). This agrees with the general rule that better resolution can be obtained when the separation is performed at $\mathrm{pH}$ around the $\mathrm{p} K_{\mathrm{a}}$ values of analytes [30]. It is interesting to note that resolution between two faster migrating analytes, $\mathrm{C}_{16}$ and $\mathrm{C}_{18}$ FAs, is somewhat better than other adjacent pairs, suggesting that diffusion might play a significant role in separations.

\subsection{Separation of FAs}

Fig. 6 shows that the separation of $\mathrm{C}_{2}$ to $\mathrm{C}_{18}$ FAs at $\mathrm{pH} 7.2$ in NACE-IA was complete in $12 \mathrm{~min}$. It is important to mention that renewing the capillary surface with $0.1 M \mathrm{NaOH}$ prior to analysis is required for improving reproducibility [e.g. RSD (migration times) of octanoic acid $<0.7 \%(n=5)]$. It is also essential for obtaining a high-speed separation in NACE-IA. The main problem associated with this non-aqueous system was the baseline instability and shift after the second system peak, which caused a difficulty to determine $\mathrm{C}_{2}$ and $\mathrm{C}_{4}$ FAs. From Fig. 6, we estimated that the limits of detection of $\mathrm{C}_{8}$ and $\mathrm{C}_{18}$ FAs are about $2.3 \mu M$ and $7.2 \mu M$, respectively. This is because the replacement of HIQSA with FAs is more efficient at higher $\mathrm{pH}$.

\subsection{Determination of $A A$}

Fig. 7 shows the separation of $3 \mu M$ AA and its stereoisomer, IAA, at pH 5.0 in NACE-ILIF, using MC540 as the fluorophores. It is surprising that the separation was complete in less than $3 \mathrm{~min}(\mathrm{RSD}<$ $1 \%$ ) and resolution was 1.3 under such low $\mathrm{pH}$ conditions. The high-speed separation is due to the high EOF after regenerating the capillary wall with $0.1 M \mathrm{NaOH}$ prior to analysis. A good control of the dissociation of $\mathrm{AA}\left(\mathrm{p} K_{\mathrm{a}}=4.25\right.$ in aqueous solution) 


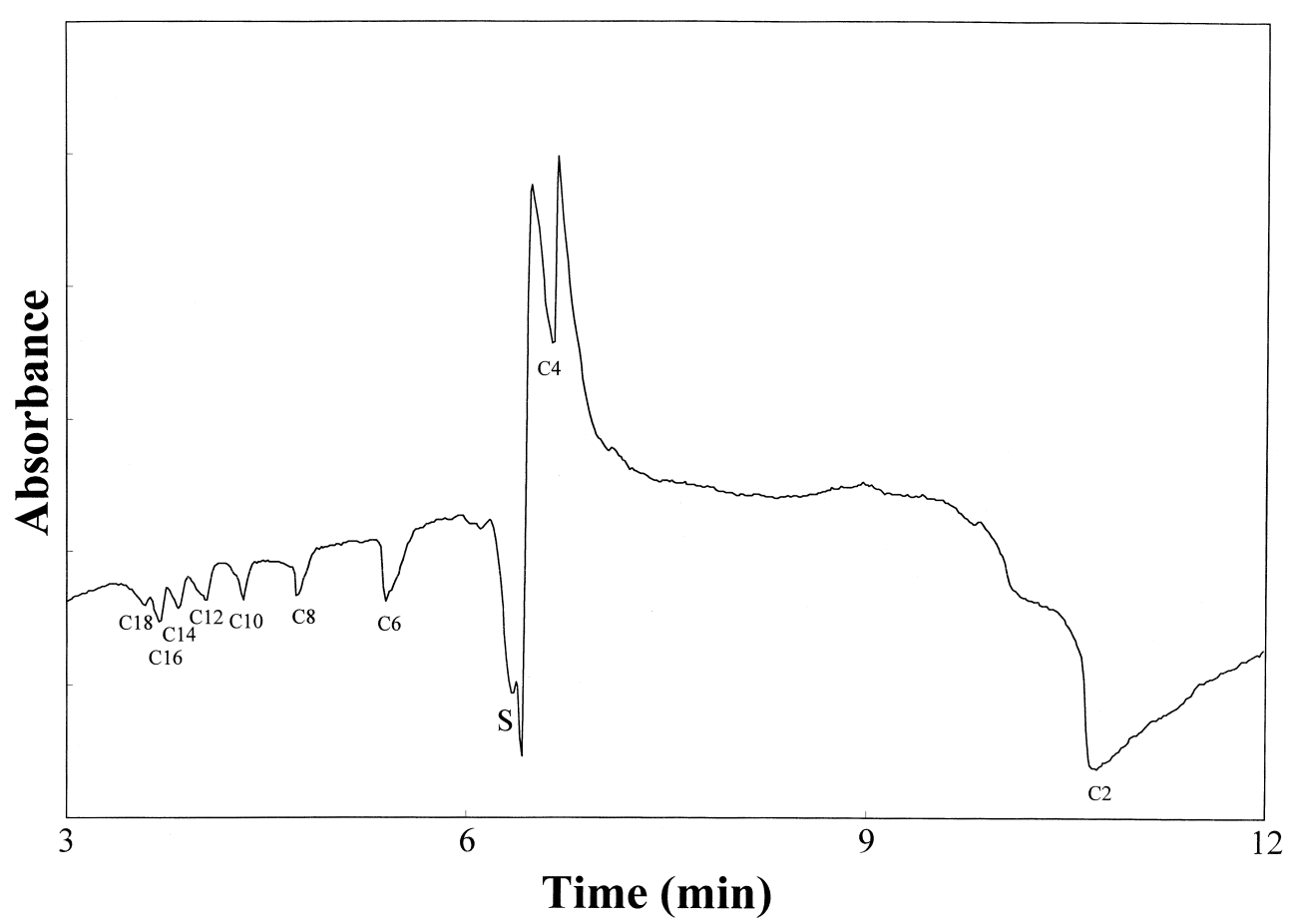

Fig. 6. The separation of $\mathrm{C}_{2}-\mathrm{C}_{18}$ FAs in NACE-IA. Conditions as in Fig. 1.

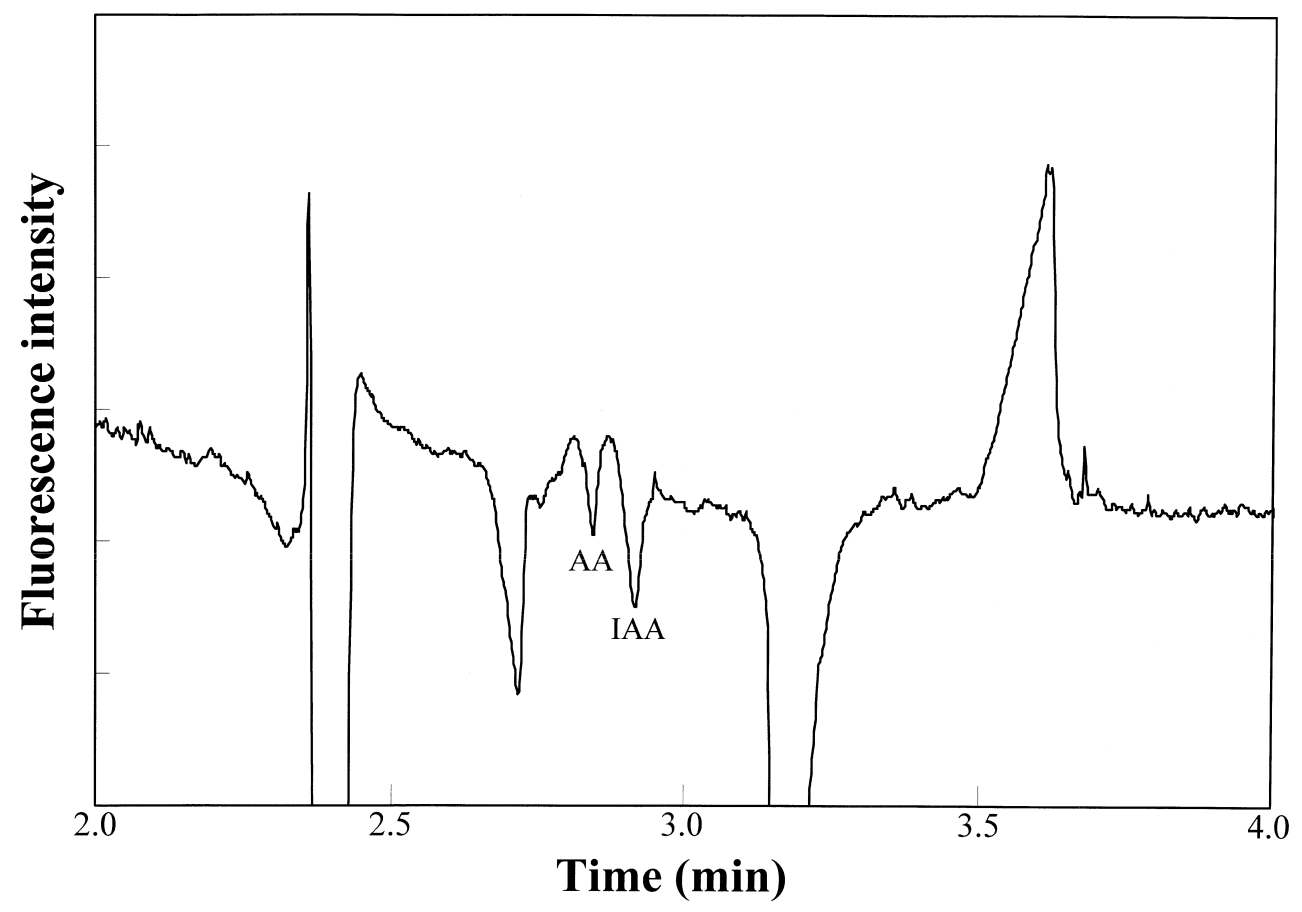

Fig. 7. The separation of AA and IAA in NACE-ILIF, using $30 \mu M$ MC540 and $40 \%$ methanol buffer solutions (pH 5.0). Other conditions as in Fig. 5. 
Table 4

Linear regression data of peak height vs. injection concentration of $\mathrm{AA}$ and IAA

\begin{tabular}{lllll}
\hline Acid & $\begin{array}{l}\text { Slope } \\
(\text { arb. unit } / \mu M)\end{array}$ & $\begin{array}{l}\text { Intercept } \\
\text { (arb. unit) }\end{array}$ & $\begin{array}{l}\text { Regression } \\
\text { coefficient }\end{array}$ & $\begin{array}{l}\text { LOD } \\
(\mu M)\end{array}$ \\
\hline AA & 4003 & 2142 & 0.9908 & 0.30 \\
IAA & 5449 & 4346 & 0.9953 & 0.17 \\
\hline
\end{tabular}

and IAA at $\mathrm{pH} 5.0$ and the migration of anions against the EOF results in better resolution results. It is advantageous to use IAA as an internal standard for the determination of AA since IAA does not naturally exist in humans or other natural products. Table 4 shows that LOD values for AA and IAA are 0.30 and $0.17 \mu M$, respectively. The LOD of AA is about ten times lower than that obtained by direct UV absorbance [17] and comparable with that from a direct fluorescence measurement after labeled with fluorophores [19]. It clearly indicates the potential of this new approach for the determination of AA in biological samples. Fig. 8 shows the separation of 1:1000 (v/v) dilution of a lemon juice spiked with 10 $\mu M$ IAA. The concentration of AA in the juice was
$76.7 \pm 0.4 \mathrm{~m} M(n=5)$. We also estimated that the concentration of AA decreased about $1.2 \%$ in $3 \mathrm{~h}$ when the juice was exposed in the air.

\section{Conclusions}

NACE-IA has been shown as a very simple, sensitive and efficient technique for the determination of FAs using $20 \% i$-PrOH and $40 \% \mathrm{ACN}$ as the organic modifier, and HIQSA as the chromophores. We also calculated the $\mathrm{p} K_{\mathrm{a}}$ values of FAs from their EPMs in NACE-IA. The determination of AA in NACE-ILIF using IAA as an internal standard suggests that this approach might be suitable for the analysis of AA in complicated samples, such as plasma. The high-speed (less than $3 \mathrm{~min}$ ) and highsensitivity $(\mathrm{LOD}=0.3 \mu M)$ separation of $\mathrm{AA}$, using such a low-cost $\mathrm{He}-\mathrm{Ne}$ laser, further indicates the potential of this new method for the analysis of a number of analytes.

The separation of acids using NACE-IA or NACE-ILIF provides advantages of low costs, fast

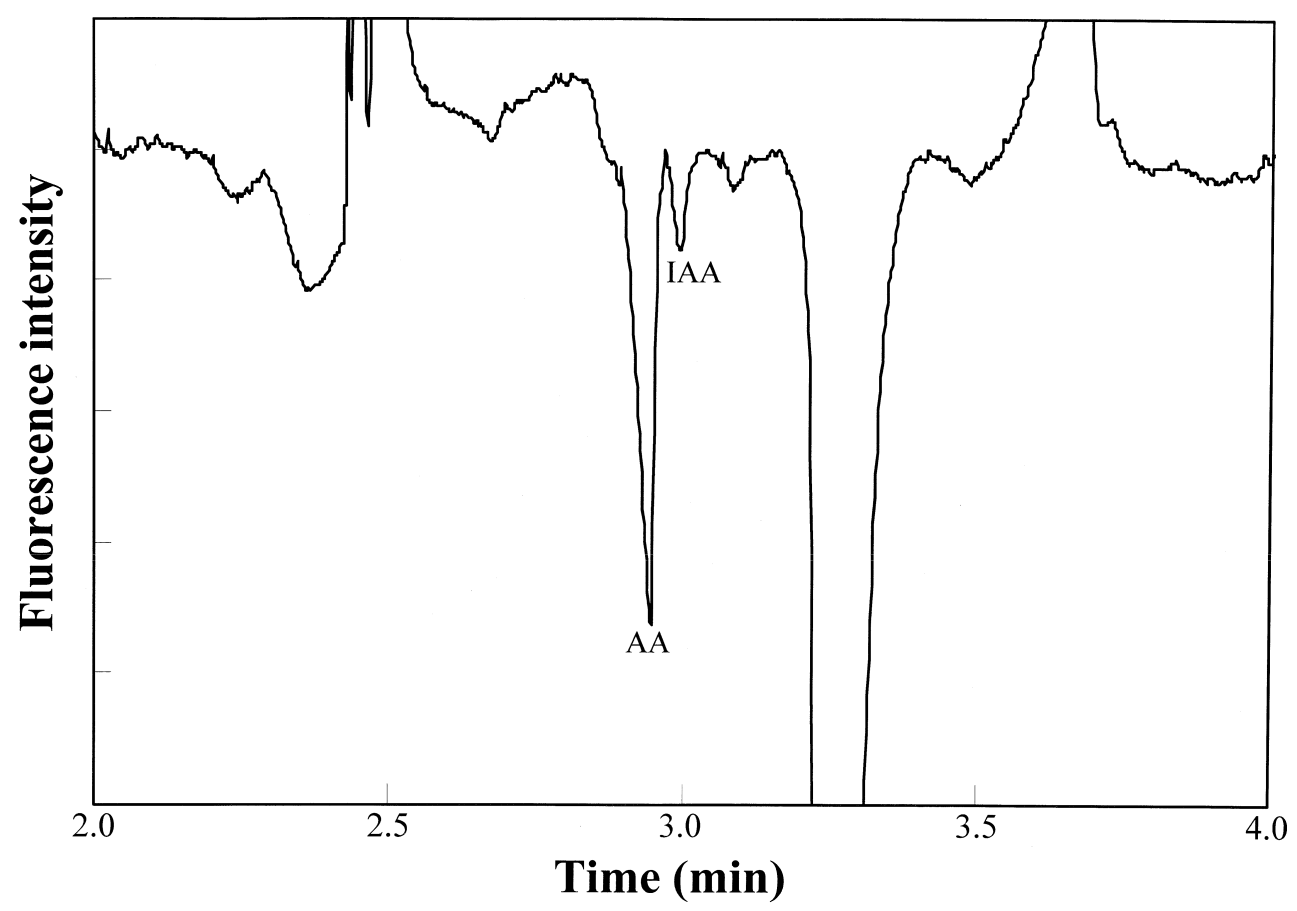

Fig. 8. The analysis of AA in a 1:1000 (v/v) diluted lemon juice spiked with $10 \mu M$ IAA in NACE-ILIF. Other conditions as in Fig. 7. 
analysis and good sensitivity. Thus it is worth further developing new techniques in non-aqueous $\mathrm{CE}$ for the analysis of small solutes. However, the problem of the instability of the baseline need to be overcome. In the further study, we plan to search for more suitable organic modifiers, chromophores or fluorophores.

\section{Acknowledgements}

This work is supported by the National Science Council of Taiwan (No. NSC88-2113-002-002).

\section{References}

[1] A. Thomas (Ed.), Ullmanns Encylopedia of Industrial Chemistry, Vol. A10, VCH, Weinheim, 1987, p. 173.

[2] E.H. Pryde (Ed.), Fatty Acids, American Oil Chemists Society, Champaign, IL, 1979.

[3] K. Hasegawa, Shokuhin Bunseki (Food Analysis, in Japanese), in: Baifukan, Tokyo, 1993, Ch. 5.

[4] N.C. Shantha, G.E. Napolitano, J. Chromatogr. 624 (1992) 37.

[5] T. Iwata, M. Yamagushi, S. Hara, M. Nakamura, J. Chromatogr. 344 (1985) 351.

[6] K. Nienela, J. Chromatogr. 399 (1987) 235.

[7] J.W. Jorgenson, K.D. Lukacs, Science 222 (1983) 266.

[8] C.W. Klampfl, W. Buchberger, Trends Anal. Chem. 16 (1997) 221

[9] R.S. Sahota, M.G. Khaledi, Anal. Chem. 66 (1994) 1141.
[10] G. Gutnikov, W. Beck, H. Engelhardt, J. Microcol. Sep. 6 (1994) 565.

[11] O. Schmitz, S. Gab, J. Chromatogr. A 767 (1997) 249.

[12] R. Roldan-Assad, P. Gareil, J. Chromatogr. A 708 (1995) 339.

[13] F.B. Erim, X. Xu, J.C. Kraak, J. Chromatogr. A 694 (1995) 471.

[14] P.A. Marshall, V.C. Trenerry, C.O. Thompson, J. Chromatogr. Sci. 33 (1995) 426

[15] E.V. Koh, M.G. Bissell, R.K. Ito, J. Chromatogr. A 633 (1993) 245.

[16] M.W. Davey, G. Bauw, M.V. Montagu, J. Chromatogr. B 697 (1997) 269.

[17] O.-K. Choi, J.-S. Jo, J. Chromatogr. A 781 (1997) 435.

[18] E. Drange, E. Lundanes, J. Chromatogr. A 771 (1997) 301.

[19] I. Koshiishi, T. Imanari, Anal. Chem. 69 (1997) 216.

[20] O. Schmitz, D. Melchior, W. Schuhmann, S. Gab, J. Chromatogr. A 814 (1998) 261.

[21] E.S. Yeung, Acc. Chem. Res. 22 (1989) 125

[22] A.M. Desbene, C.J. Morin, N.L. Mofaddel, S.R. Froult, J. Chromatogr. A 716 (1995) 279.

[23] Y.Y. Davidson, B.M. Gunn, S.A. Soper, Appl. Spectros. 50 (1996) 211.

[24] H.-T. Chang, E.S. Yeung, J. Chromatogr. B 669 (1995) 113.

[25] S.J. Gluck, K.P. Steele, M.H. Benko, J. Chromatogr. A 745 (1996) 117.

[26] M.-M. Hsieh, H.-T Chang, J. Chromatogr. A 793 (1998) 145.

[27] H.-T. Chang, H.-S. Chen, R. Lee, J. Chromatogr. A 800 (1998) 339.

[28] W.J. Lambert, D.L. Middleton, Anal. Chem. 62 (1990) 1585.

[29] R. Carabias-Martinez, E. Rodriguez-Gonzalo, J. DominguezAlvarez, J. Hernandez-Mendez, Anal. Chem. 69 (1997) 4437.

[30] J.W. Jorgenson, K.D. Luckas, Anal. Chem. 53 (1981) 1298. 